\title{
PENGEMBANGAN PROMOSI WISATA MELALUI COPYWRITING DI MEDIA SOSIAL OLEH KARANG TARUNA DESA WARNASARI KECAMATAN PANGALENGAN KABUPATEN BANDUNG
}

\author{
Winne Wardiani ${ }^{1}$, Trias Pyrenia Iskandar ${ }^{2}$, Rini Anisyahrini ${ }^{3}$, Yanti Susila Tresnawati ${ }^{4}$ \\ ${ }^{1,2,3,4)}$ Program Studi Ilmu Komunikasi, Fakultas Ilmu Sosial dan Ilmu Politik, Universitas Pasundan \\ e-mail: $\underline{\text { winne.wardiani@unpas.ac.id }}$
}

\begin{abstract}
Abstrak
Karang Taruna merupakan organisasi kepemudaan di Indonesia, yang merupakan wadah bagi para generasi muda yang berada di wilayah Desa maupun Kelurahan, sebagai wadah pembinaan dan pengembangan kepemudaan. Berdasarkan gambaran dari potensi yang ada di Kecamatan Pangalengan, maka diharapkan Karang Taruna dapat menjadi katalisator untuk mempromosikan potensi alam dan potensi wisata yang ada di Kecamatan Pangalengan untuk meningkatkan pertumbuhan ekonomi, membuka lapangan pekerjaan, peningkatan devisa dan pembangunan ekonomi daerah untuk ikut meningkatkan pertumbuhan ekonomi nasional khususnya di era 4.0. Berdasarkan uraian yang telah diuraikan pada analisis situasi, maka ada beberapa rumusan permasalahan mitra yang dapat di identifikasi, diantaranya: (1) Mitra belum memanfaatkan teknologi sosial media instagram sebagai media promosi pariwisata Desa Warnasari, (2) Mitra belum mengetahui teknik copywriting sebagai alat promosi wisata di Era 4.0. Solusi yang diharapakan diantaranya: (1) Pengarahan dan pelatihan kepada mitra dalam penggunaan teknologi sosial media instagram untuk mempromosikan potensi wisata di Kecamatan Pangalengan, (2) Bimbingan Teknis (Bimteks) dan pendampingan membuat copywriting di sosial media instagram. Berdasarkan solusi dan target luaran dari rencana pelaksanaan program pada mitra Karang Taruna, maka Tim menetapkan metode pendekatan: (1) Metode Pengarahan dan Pelatihan, (2) Metode Bimbingan Teknis (Bimtek) dan Pendampingan. Kesimpulan dari program ini: (1) Mitra dapat memanfaatkan teknologi media sosial, dengan menggunakan fitur-fitur yang ada di instagram, (2) Mitra dapat membuat konten yang menarik di media sosial intagram untuk promosi wisata.
\end{abstract}

Kata Kunci: Instagram, Karang Taruna, Media Sosial, Promosi Wisata.

\begin{abstract}
Karang Taruna is a youth organization in Indonesia, which is a place for young people who are in the Village, as a forum for youth development. Based on the description of potential are exists in Pangalengan District, it is expected that Youth Organization can be a catalyst to promote the natural potential and tourism potential in Pangalengan District to increase economic growth, open jobs, increase foreign exchange and regional economic development to help increase national economic growth especially in the 4.0 era. Based on the description that has been described in the situation analysis, there are several formulations of partner problems that can be identified, including: (1) Partners can't using Instagram social media technology as a tourism promotion media for Warnasari Village, (2) Partners do not yet know the copywriting technique as a promotional tool tours in Era 4.0. The expected solutions include: (1) Directing and training partners in the use of Instagram social media technology to promote tourism potential in Pangalengan District, (2) Technical Guidance and assistance in making copywriting on Instagram social media. Based on the solutions and target outcomes of the community service program implementation plan for partners, the team determined the approach method: (1) Guidance and Training Methods, (2) Technical Guidance Method and Mentoring. Conclusions from this community service program: (1) Partners can utilize social media technology, by using features on Instagram, (2) Partners can create interesting content on intagram social media for tourism promotion.
\end{abstract}

Keywords: Instagram, Youth Organization, Social Media, Tourism Promotion 


\section{PENDAHULUAN}

Pangalengan merupakan salah satu kecamatan yang berada di Kabupaten Bandung dan terletak di sebelah selatan Kantor Kabupaten Bandung. Di sebelah utara dibatasi oleh Kecamatan Cimaung, di sebelah selatan dibatasi oleh Kecamatan Talegong Kabupaten Garut, di sebelah barat dibatasi oleh Kecamatan Pasirjambu, di sebelah timur dibatasi oleh Kecamatan Kertasari dan Kecamatan Pacet. Kecamatan Pangalengan terbagi menjadi 13 Desa yaitu Desa Lamajang, Desa Margaluyu, Desa Margamekar, Desa Margamukti, Desa Margamulya, Desa Pangalengan, Desa Pulosari, Desa Sukaluyu, Desa Sukamanah, Desa Tribaktimulya, Desa Wanasuka, Desa Warnasari, dan Desa Banjarsari. Seluruh desa tersebut berstatus hukum definitif, yang didalamnya telah terbentuk lembaga-lembaga pemerintahan yang baik sesuai dengan peraturan yang ada.

Desa Warnasari memiliki 17 Rukun Warga dan 17 kampung yaitu Baru Taraje, Ciawitali, Cibeunying, Cibunihayu, Cidurian, Cipangisikan, Citiis, Kapas, Kiaracondong, Munjul, Neglasari, Padahurip, Palayangan, Parabon, Pasir Ucing, Singkur, dan Wanasari. Lokasi TPK Warnasari berada didepan Jalan utama Desa Warnasari di RW 02 Kampung Wanasari berjarak \pm 300 meter ke sebelah barat dari kantor Desa Warnasari. Penempatan TPK Warnasari yang terletak di lokasi pusat desa mudah dijangkau oleh para peternak di daerah utara dan selatan serta memudahkan truk untuk mendistribusikan susu yang dikumpulkan peternak ke lokasi industri pengolahan susu.

Desa Warnasari mempunyai potensi yang besar sebagai daerah penghasil produk pertanian yang dapat dikembangkan sebagai agroindustri dan agrowisata. Selain padi dan palawija, yang merupakan hasil pertanian secara umum, Desa Warnasari juga dikenal sebagai penghasil beberapa produk pertanian holtikultura. Dalam upaya pengembangan usaha tani di Desa Warnasari, pada dasarnya diperlukan keterlibatan para pelaku yang terdiri dari berbagai pihak seperti penghasil produk, pengolah, pedagang, distributor, importir dan eksportir. Pelaku-pelaku ini merupakan komponen atau subsistem yang membentuk sebuah sistem agribisnis. Sistem tersebut, di tahuntahun mendatang diharapkan agar lebih berfungsi secara optimal demi mewujudkan tingkat kesejahteraan masyarakat. Oleh karena itu, pemerintah desa Warnasari melalui program pembinaan dan pemberdayaan masyarakat akan selalu berupaya agar semua subsistem itu lebih siap dalam menjalankan perannya secara profesional.

Salah satu program pembinaan dan pemberdayaan masyarakat yang sudah pemerintah desa lakukan adalah melalui Karang Taruna. Karang Taruna merupakan organisasi kepemudaan di Indonesia, yang merupakan wadah bagi para generasi muda yang berada di wilayah desa ataupun Kelurahan, sebagai wadah pembinaan dan pengembangan kepemudaan. Berdasarkan gambaran dari potensi yang ada di Kecamatan Pangalengan, maka diharapkan Karang Taruna menjadi wadah untuk mempromosikan potensi alam dan potensi wisata yang ada di Kecamatan Pangalengan untuk meningkatkan pertumbuhan ekonomi, membuka lapangan pekerjaan, peningkatan devisa dan pembangunan ekonomi daerah untuk ikut meningkatkan pertumbuhan ekonomi nasional.

Perkembangan teknologi tentunya berdampak ke seluruh lapisan masyarakat, termasuk masyarakat di desa warnasari, khususnya para pemuda dan pemudi karang taruna desa warnasari. Dalam mempromosikan wisata desa warnasari, para pemuda karang taruna turut menggunakan media sosial. Jenis media sosial yang mereka gunakan masih cukup terbatas, yaitu Instagram.

Penggunaan media sosial sebagai media promosi wisata memiliki manfaat yang cukup besar, mengingat hampir semua individu menggunakan media sosial di dalam kehidupannya. Namun penggunaan media sosial sebagai media promosi wisata, tidaklah cukup hanya dengan posting foto saja. Diperlukan beberapa point penting untuk menunjang postingan promosi di media sosial agar menarik para pengguna media sosial.

\section{METODE}

\section{a. Metode Pengarahan dan Pelatihan}

Metode pengarahan dan pelatihan ditujukan untuk memberikan Ilmu Pengetahuan dan Teknologi (IPTEKS) dalam mengatasi permasalahan mitra, melalui peningkatan wawasan pemahaman bagi mitra mengenai penggunaan teknologi media sosial instagram, untuk promosi wisata Desa Warnasari. Pengarahan dan pelatihan dilaksanakan dalam satu ruangan di Gedung Serbaguna Desa Warnasari Kecamatan Pangalengan. 


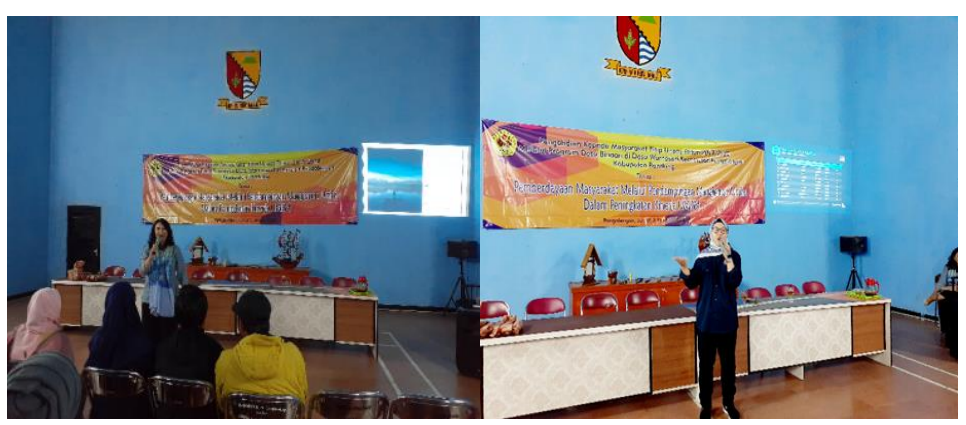

Gambar 1 Pengarahan dan Pelatihan dari Tim Sumber: Dokumentasi Tim, 2019.

Metode pendekatan ini ditetapkan oleh tim untuk mengatasi permasalahan dan solusi mencapai target luaran yang telah ditetapkan, yaitu:

1. Peningkatan kemampuan dalam menggunakan sosial media, dalam hal ini instagram memaksimalkan penggunaan media sosial sebagai media promosi wisata dengan mengarahkan dan memberikan pemahaman kepada mitra, untuk menggunakan sosial media sebagai media promosi wisata di era digital.

2. Melatih mitra dalam membuat akun promosi wisata yang menarik dengan teknik copywriting, di media sosial instagram.

\section{b. Metode Bimbingan Teknis dan Pendampingan}

Metode pendekatan ini ditujukan untuk memberikan pengetahuan mengenai Ilmu Pengetahuan dan Teknologi (IPTEKS) dalam meningkatkan kemampuan mitra menggunakan teknologi, dalam hal ini media sosial instagram .

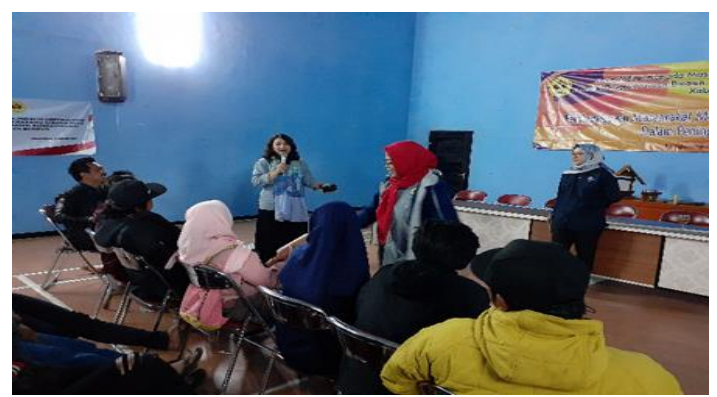

Gambar 2 Bimbingan Teknis dan Pendampingan dari Tim Sumber: Dokumentasi Pribadi Tim, 2019.

Metode yang digunakan dalam pendekatan ini terdiri dari beberapa tahapan, diantaranya:

1. Bimbingan teknis membuat konten media sosial yang menarik, mulai dari cara menempatkan gambar atau foto yang menarik, video, caption yang persuasif namun tidak berlebihan, penggunaan hash tag, dan sebagainya.

2. Bimbingan teknis dan pendampingan dalam memberikan informasi yang detail pada konten promosi di media sosial instagram.

\section{HASIL DAN PEMBAHASAN}

Setelah melaksanakan pengarahan dan bimbingan teknis kepada mitra, maka peningkatan kemampuan mitra dalam memanfaatkan teknologi media sosial instagram pun dapat terlihat dari beberapa postingan mitra. Mitra sudah mulai memanfaatkan teknik copywriting, berupa promosi dengan menggunakan kalimat persuasif yang menarik, namun tidak terkesan memaksa dan berlebihan. Seperti yang tertera pada gambar3, postingan di Instagram milik salah satu anggota karang taruna, Kang Yudi, dengan nama akun instagram incu_bahsuta13, menggunakan teknik copywriting untuk promosi wisata Desa Warnasari. Penggunaan caption yang jelas dan singkat, 
namun sangat informatif, dengan mencantumkan nomor kontak yang lengkap seperti nama akun instagram, nomor whatsapp, dan akun facebook. Pencantuman nomor kontak, dapat mempermudah para follower untuk mendapatkan informasi dengan lebih rinci, terkait harga penawaran harga dan yang lainnya. Selain itu dalam teknik copywriting, dengan mencantumkan identitas seperti nama akun media sosial dan nomor whatsapp, menunjukkan suatu "komitmen" dari sebuah promosi, bahwasannya produk tersebut ada, benar dan berwujud (bukan akun palsu).

Pemilihan kata yang digunakan pada gambar 3, sebagai "introducing" atau "perkenalan" tentang produk wisata alam yang ada di Desa Warnasari, dengan menggunakan kata-kata yang mudah di pahami dan menunjukkan "kondisi" atau "keadaan" yang sesuai dengan gambar atau foto yang ditampilkan. Foto yang diambil pun memiliki angle yang pas untuk menunjukkan keindahan alam di "New Girang" sebagai lokasi wisata yang ada di Desa Warnasari. Angle atau sudut foto menjadi bagian yang cukup penting dan dapat "menghidupkan" sebuah foto.

Pemilihan kata hingga menjadi rangkaian kalimat yang menarik, menjadi salah satu teknik copywriting yang diberikan kepada mitra karang taruna. Mitra memahami, bahwasannya promosi dengan menggunakan media sosial instagram tidak hanya bermodalkan foto yang menarik saja, namun caption atau keterangan gambar pun harus diperhatikan dengan baik untuk menarik para follower atau netizen. Terlebih lagi dengan menggunakan hashtag (\#) pada instagram, menjadi salah satu elemen penting dalam promosi.

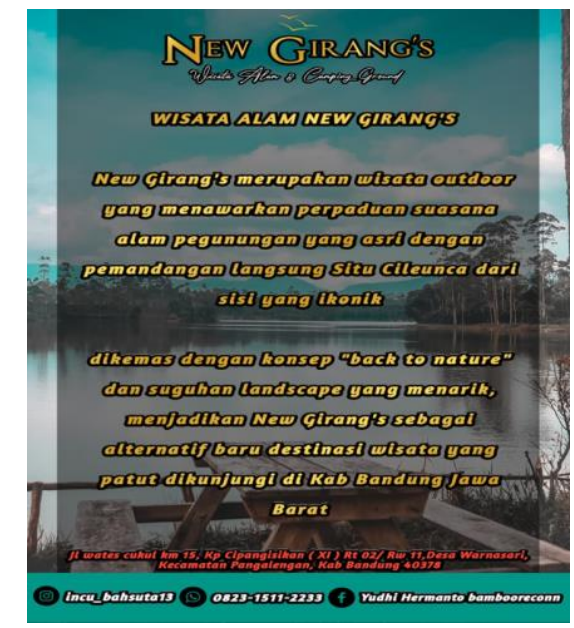

Gambar 7, postingan di Instagram anggota karang taruna, sumber:akun ig incu_bahsuta13

Deskripsi mengenai identitas suatu produk pun menjadi salah satu bagian dari teknik copywriting. Hal ini sangat diperlukan, terlebih lagi bagi mitra karang taruna yang melakukan promosi wisata pada media sosial instagram. Pada gambar 8 dan 9, mitra memposting profile dan paket wisata "New Girang" Desa Warnasari. Dalam profile tersebut mitra mendeskripsikan kondisi dan fasilitas yang ada di lokasi wisata "New Girang". Hal ini tentunya akan sangat membantu memberikan informasi kepada para "calon pengunjung" dalam hal ini netizen atau follower instagram incu_bahsuta13. Fasilitas yang ada di lokasi wisata "New Girang" di informasikan dengan cukup jelas. B Begitupun dengan paket camping yang tersedia di "New Girang" pada gambar 9, di informasikan dengan cukup jelas. Hal ini sangatlah penting, karena produk yang ditawarkan adalah "wisata camping" yang identik dengan "fasilitas terbatas", sehingga "calon pengunjung" dapat mempersiapkan dan menyesuaikan barang-barang yang akan dibawanya. 


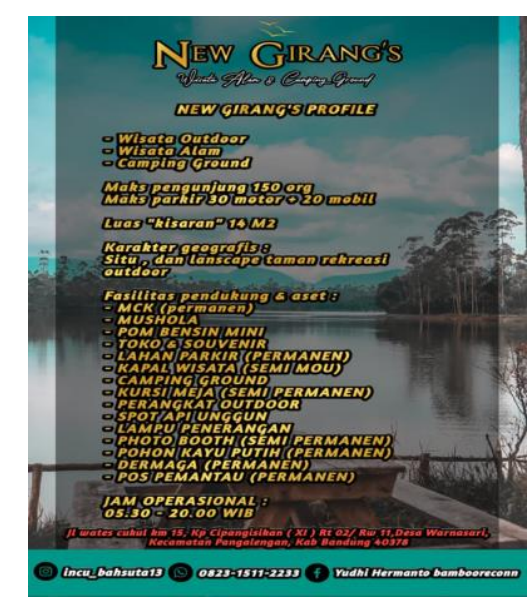

Gambar 4, postingan di Instagram anggota karang taruna, Sumber:akun ig incu_bahsuta13

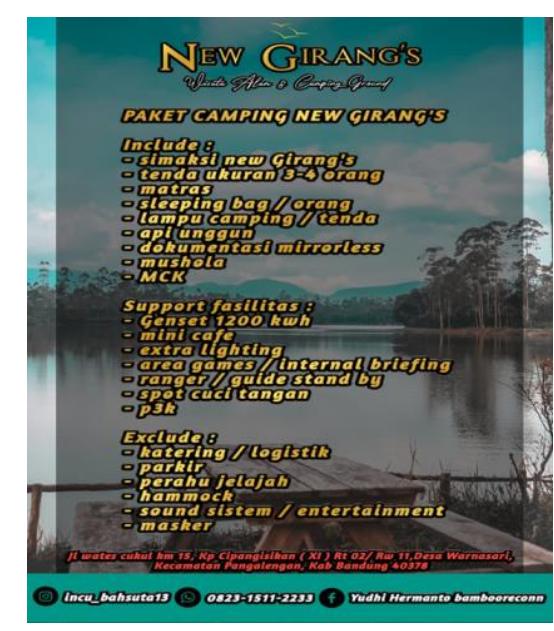

Gambar 5, postingan di Instagram anggota karang taruna, sumber:akun ig incu_bahsuta13

Penggunaan media sosial sebagai media promosi wisata memang sudah banyak sekali digunakan, namun tetap saja cara mengemas suatu produk sehingga menjadi menarik diperlukan teknik copywriting yang baik sehingga menjadi sebuah produk yang memiliki "value" lebih dibandingkan produk yang hanya melakukan promosi biasa saja.

Salah satu "value" dari produk promosi wisata mitra adalah dengan memposting peraturan di lokasi wisata "New Girang". Postingan terkait peraturan tersebut, pada gambar 10, mempertegas bahwasannya lokasi wisata "New Girang" ini memiliki tempat yang aman dan nyaman bagi semua segmen mulai dari anak kecil hingga dewasa. Bahkan bagi yang bukan muhrim, tidak diperkenankan dalam satu tenda. Hal ini menunjukkan bahwa lokasi wisata "New Girang" adalah tempat wisata alam yang ideal di Desa Warnasari. 


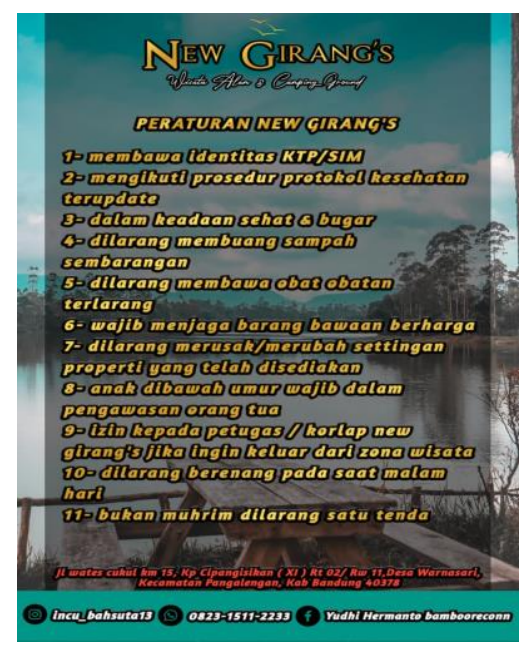

Gambar 6, postingan di Instagram anggota karang taruna, sumber:akun ig incu_bahsuta13

\section{SIMPULAN}

Berdasarkan hasil Pengabdian kepada Masyarakat (PkM) yang telah dipaparkan diatas, maka dapat disimpulkan bahwa mitra dapat memanfaatkan teknologi media sosial, dengan menggunakan fitur-fitur yang ada di instagram dan juga mitra dapat membuat konten yang menarik di media sosial intagram untuk promosi wisata.

Penggunaan fitur-fitur instagram yang digunakan oleh mitra diantaranya adalah caption yang jelas dan singkat, namun sangat informatif, dengan mencantumkan nomor kontak yang lengkap dan juga mencantumkan nama akun instagram, nomor whatsapp, dan akun facebook.

Promosi melalui media sosial instagram cukup membantu mitra dalam mempromosikan wisata di Desa Warnasari. Tidak hanya mengandalkan keindahan foto, namun mengemas satu foto dengan merangkai kata-kata pada caption foto, memerlukan sebuah tenik copywriting yang cukup baik, tentunya dengan memanfaatkan fitur-fitur yang ada di instagram tersebut.

\section{SARAN}

Promosi melalui instagram memiliki potensi yang cukup besar untuk dikenal oleh semua netizen dari penjuru dunia. Oleh karenanya, diperlukan lebih dalam lagi bimbingan teknis terkait teknik copywriting, agar pemanfaatan teknologi di media sosial instagram dapat lebih maksimal sehingga menghasilkan satu bentuk promosi yang menarik.

\section{UCAPAN TERIMA KASIH}

Puji dan Syukur kehadirat Allah SWT yang telah memberikan kesempatan dan kesehatan, sehingga pelaksanaan Pengabdian Kepada Masyarakat dan laporan Pengabdian Kepada Masyarakat ini dapat diselesaikan oleh Tim.

Pengabdian Kepada Masyarakat ini merupakan wujud dari salah satu Tri Dharma Perguruan Tinggi yang telah dilaksanakan oleh Dosen FISIP UNPAS di Kabupaten Bandung. Pada kesempatan ini kami sebagai salah satu Tim Pengabdian Kepada Masyarakat (PkM) dari Prodi Ilmu Komunikasi, memilih Karang Taruna Desa Warnasari sebagai mitra kami.

Dalam Kesempatan ini kami mengucapkan terimakasih yang sebesar-besarnya kepada:

1. Dekan FISIP UNPAS, Bapak Dr. M. Budiana, S.IP., M.Si.

2. Wakil Dekan 1 FISIP UNPAS, Bapak Kunkurat, M.Si.

3. Ketua P3M FISIP UNPAS, Bapak Dr. Abu Huraerah, M.Si.

4. Sekretaris P3M FISIP UNPAS, Ibu Ika Sri Hastuti, S.IP., M.Si.

5. Ketua Prodi Ilmu Komunikasi, Bapak Rasman Sonjaya, S.Sos., M.Si.

6. Sekretaris Prodi Ilmu Komunikasi, Bapak Vera Hermawan, M.I.Kom.

7. Lurah Desa Warnasari, Kecamatan Pangalengan, Kabupaten Bandung. 
8. Seluruh anggota Karang Taruna Desa Warnasari sebagai mitra dari Tim Kelompok kami. Terimakasih atas kerjasamanya, sehingga pelaksanaan PKM dapat terselenggara dengan baik.

Semoga Pengabdian Kepada Masyarakat (PKM) ini dapat memberikan manfaat bagi mitra Karang Taruna Desa Warnasari, Kecamatan Pangalengan, Kabupaten Bandung.

\section{DAFTAR PUSTAKA}

Burhan Bungin, Sosiologi Komunikasi. Jakarta, Kencana Prenada Media Group, 2005.

David Meerman Scott, The New Rules Of Marketing and PR. New Jersey John Wiley\&Sons,Inc., Hoboken, 2009.

Morissan, MA, Manajemen Public Relations: Strategi Menjadi Humas Profesional. Jakarta, Kencana Prenada Media Group, 2008.

Nurudin, Perkembangan Teknologi Komunikasi, Jakarta, Raja Grafindo Persada, 2018.

Poppy Ruliana, Komunikasi Organisasi, Teori dan Studi Kasus, Jakarta, Raja Grafindo Persada, 2018.

Rhenald Kasali, Manajemen Public Relations, Konsep dan Aplikasinya di Indonesia, Jakarta, Pustaka Utama Grafiti, 2006.

http://ejournal.ihdn.ac.id/index.php/PB/article/view/649 diakses pada tanggal 03/12/2019, pukul 11:58 WIB.

https://www.warnasari.desa.id/first/kategori/4 diakses pada tanggal 03/12/2019 